\title{
Pembungkaman Kaum Perempuan dalam Film Indonesia (Penerapan Teori Muted Group Dalam Film "Pertaruhan")
}

\author{
Ratna Permata Sari \\ Dosen Program Studi Ilmu Komunikasi \\ Universitas Islam Indonesia (UII), Yogyakarta
}

\begin{abstract}
:
Sex and gender are two different concepts. But for women, gender or the inherent nature of the cultural processes that give rise to various inequalities in society such as marginalization, stereotype, violence and negative labeling.

This article focuses on how role of women seen from Muted Group Theory about silencing of women in public interest in movie "At Stake (Pertaruhan)". This movie consists of four short stories such as Effort for Love, What's the point?, Miss or Mrs?, The Children's Fortune
\end{abstract}

Key Words: Gender inequalities, women, silencing, culture

\begin{abstract}
Abstrak:
Jenis kelamin dan gender adalah dua konsep yang berbeda. Tapi bagi perempuan, gender atau sifat yang melekat dari proses kultural yang menimbulkan berbagai ketidakadilan di masyarakat antara lain marginalisasi , stereotype, kekerasan dan pelabelan negative.

Fokus tulisan ini adalah bagaimana peran perempuan dilihat dari sudut pandang teori Muted Group mengenai pembungkaman kepentingan wanita di masyarakat dalam film "Pertaruhan". Film ini terdiri dari empat cerita pendek antara lain Mengusakan Cinta, Untuk Apa?, Nona Nyonya? Ragat'e Anak
\end{abstract}

Kata Kunci: Ketidakadilan gender, perempuan, pembungkaman, budaya

\section{Pendahuluan}

Proses komunikasi lintas budaya memiliki banyak aspek, salah satunya adalah lingkungan sosial dan identitas budaya. Identitas budaya antara lain meliputi identitas gender, umur, ras dan etnis, agama, kelas, regional dan identitas personal (Martin dan Nakayama, 2003:156). Tulisan ini akan lebih banyak berbicara tentang identitas gender dalam lingkungan masyarakat.

Konsep gender berbeda dengan seks (jenis kelamin). Pengertian jenis kelamin (seks) merupakan penyiratan atau pembagian dua jenis kelamin manusia yang ditentukan secara biologis yang melekat pada jenis kelamin tertentu yaitu pembagian jenis kelamin laki-laki dan perempuan. Sedangkan pengertian gender adalah suatu sifat yang melekat pada kaum laki-laki maupun perempuan yang dikonstruksi secara sosial maupun kultural contohnya konsep maskulinitas dan feminitas (Fakih, 2008:8). Perbedaan gender inilah yang menimbulkan budaya ketidakadilan bagi kaum perempuan. 
Perbedaan gender yang terjadi antara kaum laki-laki dan perempuan nyatanya melahirkan ketidakadilan gender (gender inequalities). Ketidakadilan gender termanisfestasikan dalam berbagai bentuk ketidakadilan, antara lain: marginalisasi atau proses pemiskinan ekonomi, subordinasi atau anggapan tidak penting dalam keputusan politik, pembentukan stereotipe atau melalui pelabelan negatif, kekerasan, beban kerja lebih panjang dan lebih banyak (burden), serta sosialisasi ideologi nilai peran gender (Fakih, 2008:13).

Perempuan dalam kehidupan sosial masih dinilai sebagai the other sex yang sangat menentukan mode representasi sosial tentang status dan peran perempuan. Marginalisasi perempuan yang muncul kemudian menunjukkan bahwa perempuan menjadi second sex - seperti juga sering disebut sebagai "warga kelas dua" - yang keberadaannya tidak begitu diperhitungkan (Abdullah, 2006:3).

Dalam tradisi gender kita, orang Indonesia, perepuan juga diberi sebutan wanita. Denotasi dari kata wanita adalah wani ditata atau berani ditata sehingga menimbulkan konotasi perempuan jarang diposisikan sebagai sosok yang berada di atas. Ia selalu di bawah untuk siap menerima perintah. Siapa yang memerintah? Ya suami dirumahnya. Sampai sekarang, persepsi itu masih lekat di masyarakat (Aruman 2010).

Dikotomi nature dan culture, misalnya, telah digunakan untuk menunjukkan pemisahan dan stratifikasi di antara dua jenis kelamin ini, yang satu memiliki status lebih rendah dari yang lain. Perempuan yang mewakili sifat "alam" (nature) harus ditundukkan agar mereka lebih berbudaya (culture). Usaha "membudayakan" perempuan tersebut telah menyebabkan terjadinya proses produksi dan reproduksi ketimpangan hubungan antara laki-laki dan perem- puan. Implikasi dari konsep dan common sense tentang pemosisian yang tidak seimbang telah menjadi kekuatan di dalam pemisahan sektor kehidupan - ke dalam sektor "domestik" dan "publik" dimana perempuan dianggap orang yang berkiprah dalam sektor domestik sementara laki-laki ditempatkan sebagai kelompok yang berhak mengisi sektor publik (Abdullah, 2006:4).

Ketimpangan hubungan antara laki-laki dan perempuan kaitannya berkiprah di sektor domestik dan publik terlihat dari kecilnya presentase perempuan yang menjalankan karir di sektor publik. Berdasarkan data dari The Corporate Gender Gap Report 2010, dan World Economic Forum menunjukkan presentase jumlah CEO wanita di beberapa negara yaitu negara Italia dan Braszil 11\%, Turki dan Norwegia 12\%, Finlandia 13\%, Spanyol 9\%, Jerman 6\% dan negara Jepang dan Austria hanya 4\%. Sedangkan untuk Indonesia, menurut data dari Kementrian BUMN (Badan Usaha Milik Negara), diantara kurang lebih 650 direktur BUMN, hanya kurang dari 40 orang wanita yang menempati posisi direktur BUMN atau sekitar 5\% dari jumlah keseluruhan (Rahayu, 2010).

Masih dibatasinya ruang gerak perempuan untuk berkiprah dunia karir memang masih berlaku sampai sekarang. Dan masih banyak lagi ketidaksetaraan antara kaum laki-laki dan perempuan di banyak sektor kehidupan sehari-hari. Namun, terpinggirnya kaum perempuan atas dominasi kaum laki-laki akibat dari ketidakadilan gender tersebut, bukan tidak mungkin diawali dari konstruksi bahasa yang sudah ada dibuat oleh kaum laki-laki. Dimana pada akhirnya ketidakmengertian perempuan atas bahasa yang dibuat laki-laki mengakibatkan wanita sedikit tertinggal dan terjebak pada lingkaran subordinasi kelas sosial kedua yang mana dijadikan objek 
penderita oleh kaum yang lebih berkuasa (laki-laki).

Masuknya kaum perempuan dalam kelompok minoritas atas adanya dominasi laki-laki atas bahasa yang mereka (lakilaki) buat dibahas lebih lengkap oleh Cheris Kramarae dalam "Muted Group Theory". Dalam buku Em Griffin yang berjudul "A First Look at Communication Theory", muted group theory ini dimasukkan dalam divisi cultural context sub bab gender and communication. Muted Group Theory ini oleh Em Griffin dimasukkan dalam ranah critical tradition dan phenomenological tradition. Penjelasan lebih lengkap mengenai teori ini akan dijelaskan dalam bab selanjutnya.

\section{Teori Muted Group}

Muted group theory ini dikembangkan lebih lengkap oleh Cheris Kramarae. Kramarae adalah profesor speech communication dan sosiolog di Universitas Illinois. Kramarae memulai karier penelitiannya pada tahun 1974 ketika dia memimpin sebuah studi sistematik mengenai cara-cara perempuan dilukiskan dalam kartun. Dia menemukan bahwa perempuan dalam kartun biasanya dilukiskan sebagai emosional, apologetik (peminta maaf/penyesal), dan plin-plan sedangkan pernyataan yang sederhana dan kuat disuarakan oleh laki-laki

Kramarae menyatakan bahwa bahasa secara harfiah, adalah sebuah man-made construction.Wanita, dan anggota dari kelompok subordinat lain, tidaklah bebas atau bisa mengatakan apa yang ingin mereka katakan, kapan, dan di mana, karena kata-kata dan norma-norma yang mereka gunakan telah diformulasikan oleh kelompok dominan, yaitu pria. Menurut Kramarae, kata-kata wanita tidak dihargai dalam masyarakat kita. Pemikiran wanita mengalami hal yang sama. Ketika wanita mencoba meniadakan ketidakadilan ini, kontrol pria terhadap komunikasi menempatkan wanita dalam ketidakberdayaan. Man-made language membantu mendefinisikan, menjatuhkan, dan meniadakan wanita. Wanita adalah the muted group (kelompok yang dibungkam). Tipe dominansi pria pada bahasa hanyalah satu aspek saja dari berbagai cara untuk membungkam kepentingan wanita dalam masyarakat.

\section{Muted Groups: Black Holes in} Someone Else's Universe

Ardener berasumsi bahwa ketidakpedulian terhadap pengalaman wanita merupakan masalah unik gender bagi social-anthropology. Ia kemudian sadar bahwa mutedness (kebisuan) disebabkan karena kekurangan kekuasaan (power). Orang-orang yang memiliki sedikit kekuatan tidak menyadari masalah bahasa yang mereka gunakan untuk mengungkapkan persepsi mereka. Menurut Ardener, muted structures ada di dalamnya, tetapi tidak sadar dalam penggunaan bahasa yang diciptakan kelompok dominan. Sebagai hasilnya, mereka diabaikan, disia-siakan, dan tidak terlihat. Seperti black holes in someone else's universe.

\section{The Masculine Power To Name} Experience

Kramarae berasumsi bahwa wanita melihat kenyataan di sekitarnya dengan cara yang berbeda dengan pria karena keduanya mengalami pengalaman dan aktivitas yang berbeda berdasarkan pembagian kerja (division of labor). Siapapun yang punya kemampuan naming (perluasaan penamaan), ia akan memiliki kekuasaan yang luar biasa. Selanjutnya, menurut pendekatan sociocultural, bahasa membentuk persepsi kita akan realitas. Maka, pengabaian terusmenerus terhadap kata-kata, dapat membuat pengalaman itu menjadi unspoken, bahkan unthought. 
Men As The Gatekeepers of Communication

Meskipun banyak public mode of expression yang mendeskripsikan pengalaman feminin, wanita akan tetap di-muted ketika mode of expression mereka diabaikan. Menurut Dorothy Smith, pria menganggap penting hanya pembicaraan yang diucapkan pria. Apa yang dilakukan pria hanya relevan bagi pria, ditulis oleh, tentang, dan untuk pria. Pria didengarkan dan mendengarkan satu sama lain.

\section{The Unfulfilled Promise of The Internet}

(1). Information Superhighway, dimana masih sulit bagi wanita untuk mengakses pelayanan internet serta situs tidak dirancang secara khusus untuk menyambut wanita. (2). The New Frontier, pria berpandangan bahwa komputer dan online tidak cocok bagi wanita. (3). Democracy, karena kaum wanita belum menjadi kelompok yang 'membuat' pengetahuan, maka wanita justru harus lebih berhati-hati ketika menelusuri dunia maya. (4). A Global Community, lewat internet, wanita bisa saling berbagi pengalaman dengan orang lain di seluruh dunia. Namun internet menghadirkan komunitas yang telah eksis tanpa mendorong pihak-pihak yang tidak hadir untuk berpartisipasi. Untuk mendapat kepercayaan, para pria membuat site 'women only' untuk menipu wanita dan mendapatkan kepercayaan mereka.

Women's Truth Into Men's Talk: The Problem Of Translation

$$
\text { Dominasi maskulin pada }
$$
komunikasi publik membuat wanita harus mentransformasi model bahasanya agar diterima pada sistem pria. Wanita harus berhati-hati dalam pemilihan kata karena "What women want to say and can say best cannot be said easli because the language template is not of their own making".

Speaking Out In Private: Networking With Women

Menurut Kramarae, wanita cenderung mencari cara yang berbeda dalam mengekspresikan pengalamannya kepada public melalui diary, jurnal, surat, cerita, gossip dll. Namun pria tetap berusaha memahami maksud wanita karena mereka sadar bahwa mendengarkan wanita itu perlu untuk membangun kehormatan yang lebih besar lagi untuk dirinya.

Speaking Out in Public: A Feminist Dictionary

Tujuan utama dari muted group theory adalah untuk mengubah manmade linguistic system yang membuat wanita tidak bisa maju dan berkembang. Kemudian Kramarae dan Paula Treichler membuat kompilasi kamus feminis yang menawarkan definisi untuk kata-kata wanita sekitar 2.500 kata untuk menggambarkan kreativitas bahasa dan memperkuat status kebungkaman mereka.

Sexual Harrasment: Coining A Term To Label Experience

Wanita telah menjadi objek tetap pelecehan seksual. Ini terjadi karena wanita tidak memiliki kekuasaan (power) yang besar dalam masyarakat sehingga sering dilecehkan dan direndahkan. Istilah sexual harassment digunakan pertama kali pada sebuah kasus di pengadilan pada akhir tahun 1970. itu adalah kata legal pertama yang didefinisikan oleh wanita. 
Perempuan Dalam Film Pertaruhan Dari Sudut Pandang Teori Muted Group

Wacana tentang ketimpangan kaum perempuan ini sudah cukup banyak diperbincangkan di media massa Indonesia. Perbincangannya mulai dari talk show di televisi, di media cetak dan tak ketinggalan melalui media film. Film "Pertaruhan" adalah salah satu dari sedikit film dokumenter buatan anak negeri yang berbicara mengenai posisi minoritas perempuan saat ini, mulai dari kelas menengah ke bawah hingga menengah ke atas, mulai dari perempuan itu lahir hingga dewasa.

Film "Pertaruhan" ini, At Stake (dalam bahasa inggris), adalah produksi Kalyana Shira Films yang merupakan karya kolektif dari Workshop Project Change 2008. Dalam film ini terdapat empat cerita pendek yang masing-masing mengangkat tema yang berbeda-beda pula. Antara lain: cerita "Mengusahakan Cinta" yang disutradai dan ditulis oleh Ani Ema Susanti, cerita "Untuk apa?" yang disutradai dan ditulis oleh Iwan Setiawan dan Muhammad Ichsan, cerita " Nona Nyonya?” yang disutradai dan ditulis oleh Lucky Kuswandi dan cerita " Ragat'e Anak" yang disutradai dan ditulis oleh Ucu Agustin.

(1). Cerita pertama dalam film "Pertaruhan" ini berjudul "Mengusahakan Cinta" bercerita tentang dua wanita yang bekerja sebagai TKW (Tenaga Kerja Wanita) di negara Hongkong. Wanita pertama bernama Ruwati Rahayu (43tahun) mempunyai masalah komunikasi ketika dia harus memberitahu calon suaminya bernama Yanto tentang operasi penyakit miom melalui vagina padahal Wati masih perawan.

Wati: "Hasil terakhir dari rumah sakit mengatakan saya harus operasi, otomatis ya saya takut dilihat vagina saya. Jangan sampai orang lain tahu dulu sebelum calon suami. Proses saya menjelaskan ke calon suami tentang operasi saya lewat vagina sampai sekarangpun dia belum mau menerima. Sampai temen saya pulang ke Indonesia kemudian dia mampir kerumah calon suami, dan calon suami saya masih tanya sama temen saya apa bener-bener operasi. Saya kan masih kaget. Padahal saya pulang tinggal beberapa hari lagi. Sampai sekarangpun dia masih belum jelas atau belum terima”.

Yanto: "Sepengetahuan saya mbak Wati itu sehat-sehat saja,tahu-tahu akhir-akhir pas mau pulang itu. Namanya sakit sejenis tumor itu kan gak mendadak gitu. Dia minta izin untuk operasi lewat vagina, karea dia kan masih lajang dan katanya belum pernah berhubungan badan dengan lakilaki. Jadi istilahnya masih perawan lah. Waktu itu dia bilang mau dibedah, terus sekang dia bilang tidak jadi. Tapi ketika saya tanya penyakitnya yang sebesar telur itu hilang. Tapi operasinya lewat "itu" (vagina). Masa sih? Saya jadi nggak percaya. Makanya saya minta penjelasannya. Lebih baik bicara apa adanya saja".

Penjelasan: Jika dilihat dari kacamata muted group theory, perdebatan masalah ini bisa dimasukkan ke dalam Women's Truth Into Men's Talk: The Problem Of Translation dimana dominasi maskulin pada komunikasi publik membuat wanita harus mentransformasi model bahasanya agar diterima pada sistem pria. Dalam kasus ini, Wati harus berulang kali menjelaskan kepada Yanto bagaimana prosedur operasi tersebut yang harus lewat vagina. 
Dan itu pun, Yanto juga belum mau menerima penjelasan Wati dengan mudah. Disini, penulis melihat Yanto menjadi tidak percaya apa yang dikatakan Wati, hingga sampai meminta Wati untuk berbicara apa adanya seakan-akan Wati menyembunyikan sesuatu perihal penyakit dan cara operasinya.

Wanita kedua dalam cerita pertama bernama Riyantini (30 tahun). Dia memilih bekerja sebagai TKW dinegeri orang karena mendapat perlakuan yang tidak baik dari mantan suaminya.

Riyantini: "Aku nikah umur 14 tahun, suami saya selisih 12 tahun. Tapi pernikahan saya dijodohin. Akhirnya dia menyeraikan saya, di surat cerainya dia bilang kalo aku selingkuh. Tapi aku nanya ke dia, kalo aku selingkuh mana buktinya. Ada buktinya gak. Jangan asal ngomong. Jangan cuma dengerin orang. Aku jadi istri dia tu kayak budak. Kalo waktu dia mau aja, dia minta aku. Waktunya aku disuruh kerja, ya aku kerja. Tapi gilirannya aku butuh, dia kayak gitu. Jadi mending aku jadi babu, jadi budak di luar negeri, aku dapet gaji”.

Penjelasan: Untuk kasus Riyantini, dalam teori muted group bisa dimasukkan dalam Black Holes in Someone Else's Universe. Kaum perempuan yang mengalami pembungkaman terjadi karena kurangnya kekuasaan. Dikarenakan kurangnya kekuasaan Riyantini sebagai istri, dia tidak bisa berbuat banyak untuk dirinya sendiri, dan dengan mudah disuruh-suruh serta diperlakukan buruk seperti budak oleh suaminya sendiri. Kekuasaan besar suaminya atas putusan cerai itulah yang membuat Riyantini menjadi terpojok atas fitnah yang diarahkan kepadanya.

(2). Cerita kedua berjudul "Untuk Apa?" bercerita tentang pro dan kontra adanya khitan atau sunat pada perempuan. Di satu sisi budaya atau tradisi mewajibkan khitan perempuan, tapi dari sisi medis \menganggap hal itu haram karen a justru melukai organ vital perempuan.

Della (38 tahun): "Aku masih inget itu sekitar 11tahun, ayah mengajakku dan 3 adik perempuanku ke klinik kecil di bukit tinggi. Ayah berkata: Ayah memutuskan kalian khitan karena menganggap itu adalah bagian untuk menyempurnakan diri kalian sebagai perempuan. Berpuluh tahun aku terus mencari pengertian menyempurnakan diri sebagai perempuan bukankah kita sudah dibikin sedemikian sempurna oleh Allah".

Nong Darrol Mahmada (Liberal Islam Network Activist): "Khitan itu bentuk kontrol atas wilayah privat domestik perempuan. Khitan perempuan itu bukan untuk dirinya, tapi untuk orang lain (pasangan)".

Penjelasan: Sebagian besar khitan perempuan ini dilakukan pada saat si anak masih kecil, bahkan beberapa kasus dilakukan pada saat bayi. Pada saat itu, tentu saja seorang perempuan belum tahu dan mengerti bagaimana khitan itu dan apa kegunaannya. Keputusan dari orang tua dan keharusan di beberapa tradisi "memaksa" perempuan melakukannya. Dalam hal ini, perempuan telah dibungkam karena masyarakat menganggap bahwa Men As The Gatekeepers of Communication karena hampir sebagian besar pemuka adat adalah para laki-laki dan pengambil keputusan di dalam 
suatu keluarga juga adalah seorang ayah maka beberapa tradisi yang harus dilakukan oleh seorang perempuan sebagian besar diputuskan oleh kaum laki-laki. Hal itu terjadi karena atas adanya dominasi dan peran gatekeeper mereka (kaum laki-laki) atas komunikasi dan informasi yang berkembang di masyarakat.

(3). Cerita ketiga berjudul "Nona Nyonya?" bercerita tentang perdebatan serius dalam pemeriksaan pap smear, antara status nona atau nyonya mulai dari pendaftaran formulir hingga di dalam ruang dokter.

Dokter: "Ada masalah apa?

Naya: "Saya mau paps mear"

Dokter: "Kamu mau pap smear? Buat apa pap smear? Kamu udah sering hubungan?

Naya: "Iya"

Dokter: "Orang tua kamu gak bingung apa kamu pap smear?

Naya: "Orang tua saya kan gak ada diruangan ini”

Dokter: "Udah tau belum orang tuanya pernah berhubungan?

Naya: Apa hubungannya

Dokter: "Mbak kan udah pernah melakukan hubungan. Karena statusnya mbak Naya kan masih gadis, ibu mbak harus tau kalo mbak mau pap smear..

Naya: "Kan saya sudah 26 tahun. Apa hubungannya orang tua saya tau? apa untungnya dokter pake nanya orang tuanya tahu apa belum? Seakan-akan orang tua saya bisa menghukum dokter.

Dokter: Kalo misalnya nanti ada hasilnya. Semisal perlu tindakan lanjutan. Kita bisa lebih mudah jika juga ditanganin oleh orang tua.
Naya: "Itu kan nanti, Bapak itu saya belum mulai pap smear udah dibilangin kalau nanti ada kanker ganas gimana gak serem.

Dokter: "Kalo kita orang timur, selama kamu belum menikah itu masih dalam hubungan orang tua.

Naya: Itu kan secara norma budaya. Tapi kalo secara legal gimana? Sampai umur berapa?

Dokter: "Sampai menikah"

Naya: Kalau saya sudah 47 tahun tapi saya belum menikah trus orang tuanya udah gak ada trus siapa.

Dokter: Tetap tidak bisa

Naya: Apa kalo gitu dianjurkan lebih gampang pas saya masuk saya bilang nyonya aja ya pak, pas ngisi formulir.

Kesimpulannya seorang wanita itu sebelum menikah, dia tidak pernah independent. Kalo wanita itu masih single, usia berapapun harus ada pendampingan orang tua (Naya).

Penjelasan: Dialog atau perdebatan panjang antara dokter dan pasien diatas dapat dimasukkan dalam Face Negotiation Theory (FNT) dimana kedua-duanya saling Dominating: Competing to win when people's interest conflict. Face Negotiation ini sendiri terjadi karena perbedaan budaya antara dokter yang sudah cukup tua dan berpikiran kolot yang menganggap periksa pap smear sampai umur berapapun harus didampingi orang tua sedangkan bagi pasien (Naya) perempuan berumur 26 tahun ini berpikir bahwa ketika perempuan sudah mandiri dia tidak perlu pendampingan orang tua untuk melakukan pemeriksaan pap smear. Disini perempuan dibungkam dalam mencari 
informasi kesehatan bagi diri sendiri hanya karena norma budaya dan peraturan rumah sakit yang mengharuskan pemeriksaan pap smear dilakukan saat si perempuan sudah menikah atau dalam pendampingan orang tua. The Masculine Power To Name Experience dalam kasus ini bisa dipakai karena adanya laki-laki dan perempuan mengalami pengalaman dan aktivitas yang berbeda berdasarkan pembagian kerja (division of labor). Pria yang dari dulu diberikan akses besar dalam mencari ilmu, pengetahuan dan kebebasan dalam bekerja memiliki pengalaman yang mampu mendominasi peran perempuan yang saat ini masih ada keterbatasan dalam memperoleh pengetahuan dan informasi.

(4). Cerita ke empat dalam film ini berjudul "Ragat'e Anak", menceritakan perjuangan ibu yang bekerja keras demi menghidupi anaknya, pagi hari bekerja memecah batu sedangkan malam hari menjadi Wanita Pekerja Seks (WPS) di pemakaman Bolo, Tulungagung.

Samira: "Dulu saya pernah punya hubungan sama kiwir ${ }^{1}$, namanya Gatot ya lama, ada 7 bulan. Trus aku lari hindarin dia, gak kuat. Dapat uang setor, uang yang pegang dia. Kalo mau makan aja harus bilang koq. Laper aja bilang: "mas ak laper minta uangnya. Cuma dikasih dua ribu, habis itu dipukul, padahal itu uangku”.

Penjelasan: Dalam Sexual Harrasment: Coining A Term To Label Experience dijelaskan bahwa wanita telah menjadi objek tetap pelecehan seksual. Ini terjadi karena wanita tidak memiliki kekuasaan (power) yang besar dalam masyarakat sehingga sering

\footnotetext{
${ }^{1}$ Laki-laki tidak resmi yang menjadi pendamping WPS (Wanita Pekerja Seks)
}

dilecehkan dan direndahkan. Kekerasan fisik, mental dan seksual kerap terjadi pada kaum perempuan. Dalam kasus Samira ini lebih mengenaskan karena secara materi dia (Samira) yang mencari uang untuk kebutuhan sehari-hari serta menghidupi Gatot (kiwiran) tapi uang hasil jerih payahnya dikontrol oleh Gatot dan sering menerima pukulan jika Samira melakukan sesuatu yang salah. Bahkan oleh pria yang bukan suami resminya saja, wanita kerap dilecehkan. Belum lagi terjadi banyak praktek pelecehan yang dilakukan suami kepada istrinya yang juga sudah dilegalkan oleh masyarakat sendiri.

\section{Penutup}

kaum $\begin{gathered}\text { Ketidakadilan yang menimpa } \\ \text { perempuan rupanya sudah }\end{gathered}$ mendarah daging dalam budaya kita. Perempuan yang dianggap sebagai warga negara kelas dua masih sering tidak dianggap, sering direndahkan, dilecehkan dan tidak dihargai hak-haknya. Salah satu teori komunikasi dan gender yang membahas tentang perempuan adalah Teori Muted Group. Dalam teori ini dijelaskan bahasa adalah buatan dan kontruksi kaum lak-laki.

Untuk kasus pembungkaman kaum perempuan, penulis mengambil contoh film "Pertaruhan". Dalam film yang mengandung empat cerita yang berbeda ini digambarkan bagaimana perempuan "dibungkam". Dalam beberapa aspek (walau tidak banyak), dalam film tersebut melalui dialog dan narasi, penulis berusaha melihat pembungkaman perempuan karena adanya bahasa yang dikonstruksi oleh laki-laki. Isi film ini hanyalah sekelumit penggambaran nyata bagaimana saat ini perempuan masih direndahkan dan 
eksistensinya dalam kehidupan unsur budaya suatu kelompok masyarakat bermasyarakat belum banyak diperhitungkan. yang memberikan jurang pemisah yang cukup jauh antara konsep gender antara

Konstruksi bahasa oleh laki-laki hanyalah satu aspek saja dari berbagai cara untuk membungkam kepentingan perempuan dan laki-laki juga ikut ambil bagian yang besar dalam membungkam kaum perempuan.

\section{DAFTAR PUSTAKA}

Abdullah, Irwan. 2006. Sangkan Paran Gender. Yogyakarta: Pustaka Pelajar

Aruman, Edhy. 2010. "Mendobrak Langit - Langit Kaca” dalam Majalah Swa No.08/XXVI/15-28 April 2010, hal.22

Fakih, Mansour. 2008. Analisis Gender dan Transformasi Sosial. Yogyakarta: Insist Press

Griffin, Em. 2009. A First Look At Communication Theory. Boston: McGraw-Hill Higher Education

Martin, Judith $\mathrm{N}$ dan Thomas K Nakayama. 2003. Intercultural Communication In Context. Boston: Mc Graw Hill

Rahayu, Eva Martha. 2010. "Panggil Mereka: Women On Top" dalam Majalah Swa No.08/XXVI/15-28 April 2010, hal.29 